\title{
Homeland Security and Emergency Management Grant Allocation
}

\author{
Barry Ezell \\ Old Dominion University \\ Kaleen Lawsure \\ Old Dominion University
}

\begin{abstract}
The Federal Emergency Management Agency provides grants to fund all-hazards projects. For the Commonwealth of Virginia, these grants are administered by the Virginia Department of Emergency Management. Each year, under the leadership of the governor's office, VDEM allocates millions of dollars to enhance homeland security across the Commonwealth to promote transparency and public safety stakeholder involvement for the allocation of these critical grant funds. A continuous challenge has been ensuring that investments are consistent with federal, state, and local priorities while balancing the differences in stakeholder discipline, risk profile, resources, and access to information. To achieve an objective and transparent decision rationale and to give decision makers confidence that public funds are being well spent; VDEM uses a portfolio decision analysis methodology for grant allocation. The approach supports continuous improvements to the grant process from initial kick-off to final funding decision, using a multi-objective decision analysis framework for benefit-cost analysis. This methodology has enabled decision makers to make traceable decisions consistent with the priorities of the emergency management community.
\end{abstract}

Keywords: Emergency Management, Grant Management, Multi-Objective Decision Analysis

\section{INTRODUCTION}

The Department of Homeland Security (DHS) through the Federal Emergency Management Agency (FEMA) provides grant allocations to states, federally recognized tribes, local communities, and certain private non-profits to fund emergency management initiatives. The Virginia Department of Emergency Management (VDEM) is the State Administrative Agency (SAA) for these grant programs. As such, VDEM is tasked with ensuring that all projects submitted to FEMA stand the best chance of winning approval by aligning with federal, state, and local priorities and guidance. Projects submitted to FEMA must also be justifiable by way of risk assessments, benefit-cost analysis, and mitigation plans.

Since 2009, there has been a consistent effort to establish and refine a transparent and stakeholder driven process for limited but critical funds. This effort began with the Hampton Roads Urban Area Security Initiative (UASI) program in which a multi-objective decision analysis (MODA) methodology was later adapted for the State Homeland Security Program (SHSP) in 2012, and the Hazard Mitigation Assistance (HMA) program in 2017. The focus of this paper is on the SHSP and HMA grant programs, 
and the process undertaken to support the grant cycle from initial kick-off to final selection of projects submitted to FEMA.

Grant allocation is a challenging process as goals, objectives and priorities shift from one grant program or grant cycle to another, and values and preferences vary amongst stakeholders. The grant allocation process is made further challenging due to the inherent subjectivity of the proposal submission and selection process. Decision makers, emergency managers, planners, first responders, volunteer organizations, community organizations, citizens, and numerous others have their own perspectives which can vary widely based on geography, demographics, discipline, expertise, risk \& vulnerability, capabilities and resources, history of hazards, and their mission areas of concern. Additionally, a proposal is only as effective as the proposal writer's ability to communicate the necessity and value of the project, which may or may not be consistent with a decision maker's perception of necessity or value. Knowledge, perspectives, context, and access to information make grant allocation a complex sociotechnical challenge.

While subjectivity can never be totally eliminated from this process, it can be mitigated by establishing a project scoring system that can be used to rank proposals within a portfolio relative to others based on stakeholder priorities. Therefore, a more systematic and objective methodology by which to justify grant allocation decisions has been implemented. This methodology uses multidisciplinary stakeholder engagement as critical inputs informing model parameters and ensuring that parameters are set based on group values and preferences. Additionally, the overall methodology allows for enough flexibility that modifications can be easily made as the decision making environment changes.

\section{State Homeland Security Program}

The State Homeland Security Program (SHSP) is funded under the Homeland Security Grant Program (HSGP) (DHS, 2018b). The purpose of the program is to provide funding to support the building, sustainment, and delivery of core capabilities essential to achieving the National Preparedness Goal of "A secure and resilient Nation with the capabilities required across the whole community to prevent, protect against, mitigate, respond to, and recover from the threats and hazards that pose the greatest risk" (DHS, 2015). Funding for SHSP contributes to planning, equipment purchase, training, exercise, and management and administration related to preparedness activities, especially as they relate to terrorism.

\section{Hazard Mitigation Assistance}

The Hazard Mitigation Assistance Program (HMA) provides funding for two different types of disaster mitigation grants (FEMA, 2015). The first are annual grants that are made available to take actions before a disaster in order to reduce risk to individuals, property and infrastructure, and reduce reliance on Federal funding from future disasters. Annual grants include the Pre-Disaster Mitigation (PDM) (DHS, 2018c) and the Flood Mitigation Assistance (FMA) (DHS, 2018a) grant programs. The second grant type is a post-disaster Hazard Mitigation Grant Program (HMGP) (FEMA, 2015). The purpose of the HMGP is to help communities implement hazard mitigation measures following a Presidential Disaster Declaration. ${ }^{1}$

\section{GRANT ALLOCATION PROCESS}

The State Homeland Security Program (SHSP) grant allocation process has been continuously evolving since its inception in 1999, especially so since 2012 when a formal decision support process was put into action enabling senior leadership to better track and quantify funding decisions. Prior to 2012, funding decisions were made by executive senior leadership, at the state level, based on group expertise and informal evaluation of project value. In 2012, a formal scoring process for project evaluation was implemented. The formal process used a multi-objective decision model to score projects by weighted criteria, selected by senior leadership, that were judged to be consistent with federal, state, and local priorities. In 2014 the project scoring process was shifted from the purview of senior leadership, to peer 
review by multidisciplinary public safety stakeholders across the Commonwealth. This change was designed to promote transparency and improve stakeholder awareness. In 2015, another major change was made to have stakeholders, rather than senior leadership, identify, define, and weight the criteria used to score projects. In addition, stakeholders provided valuable input on various grant topics including grant ground rules. In 2017, the overall process was adopted by the Hazard Mitigation Assistance (HMA) grant program.

The following sub-sections describe the grant process as applied to SHSP and HMA grants. The grant allocation process is a multistep process consisting of eight steps including 1) stakeholder workshop, 2) application submission 3) eligibility screening, 4) peer review, 5) model calculations, 6) analysis, 7) funding decision, 8) projects submitted to FEMA.

\section{Stakeholder Workshop}

An annual stakeholder workshop includes multidisciplinary public safety and emergency management stakeholders from the local, regional and state level throughout the Commonwealth. Workshop objectives vary, but typically include program updates, grant guidance ( TABLE 1, TABLE 3), overview of grant methodology, briefing of past results, open discussion of grant topics, and establishment of criteria definitions (TABLE 2, TABLE 4), values and weights for the upcoming grant cycle.

\section{SHSP Workshop}

TABLE 1

2018 SHSP GUIDANCE

\begin{tabular}{|l|l|}
\hline 2018 SHSP Grant Guidance & \\
\hline Total Allocation & $\$ 7,120,000$ \\
\hline State Portion $\mathbf{2 0 \%}$ & $\$ 1,424,000$ \\
\hline Local Pass Through 80\% & $\$ 5,696,000$ \\
\hline $\begin{array}{l}\text { Special Operations Teams \& Fusion } \\
\text { Center }\end{array}$ & $\$ 2,500,000$ \\
\hline Exercise Programs & $\$ 900,000$ \\
\hline Competitive Grant Funds & $\$ 2,296,000$ \\
\hline
\end{tabular}

SHSP workshop open discussions have resulted in the following grant rules:

- Competitive projects will only be funded at a MINIMUM of $\$ 10,000$, and a MAXIMUM of $10 \%$ of competitive grant funds.

- A $10 \%$ cap of competitive grant funds will be placed on all Community Emergency Response Team (CERT) project awards.

- Projects that are divided into multiple proposals are not allowable. Applicants must include all project components in one proposal.

- Projects will be designated as competitive or Special Operations Team (SOT) projects.

- Competitive projects will be peer reviewed. Individual peer reviewers will evaluate projects based on non-regional criteria by reviewers outside of the project region.

- Competitive projects will also be reviewed by subject matter experts from the project region on regional criteria. For interoperability communications and cyber security, projects will be evaluated by respective subject matter experts. SMEs will not split any jurisdiction's projects if dividing projects into separate groups for review. 
- SOT projects are local resources with documented agreements with the state and will therefore be internally reviewed by VDEM. Only one project per region per team may be submitted, and include fusion centers, hazmat, Incident Management Teams (IMT), radio cache, and urban search \& rescue/technical rescue.

- State agencies are eligible to partner with local or regional fiduciary agents on projects but must not function as the fiduciary agent as this would put them in competition with localities already competing for limited funds.

- The bottom $40 \%$ of lowest scoring projects will be eliminated prior to benefit-cost ranking.

\section{TABLE 2 2018 SHSP CRITERIA DEFINITIONS}

\section{SHSP Scoring Criteria Definitions}

Risk - The project links to known/emerging risk with a nexus to terrorism. The project fits state, region, local, and tribal priorities and/or established documented risk. Documentation is provided as appropriate. (e.g. THIRA, Risk Assessments, Emergency Operations Plan, etc.). The project addresses risk in terms of threat, vulnerability and consequence.

Benefit - The project benefits the jurisdiction, region and state. The project benefits the community, region, staff and other stakeholders.

Vetted Regionalism - 1) The proposal identifies a capability gap, 2) the project addresses the gap, and 3) the project includes letters of concurence from jurisdicatuons identified in scope. Y/N (All three must apply)

Resource Sharing - The project has a credible plan to share resources. The plan has documentation (e.g. MOUs, contracts, etc.) that demonstrates collaboration and/or agreement from multiple jurisdictions, and/or multiple regions, and/or multiple disciplines (fire, police, emergency medical services).

Scope - The proposal identifies specific jurisdiction(s), the impact to the jurisdiction(s) \& how the interaction occurs.

Capability Linkage - The project links to core capabilities and preparedness goals with a nexus to terrorism.

Sustainment - Consider whether this project sustains or enhances a current project or if it is a new project. If the project is new, the proposal describes how any equipment, licenses, training and other features will be maintained and upgraded after the period of performance? If this is sustainment of a current project, the proposal describes the outcomes of the previous period(s) of performance and ongoing sustainment plan.

Whole of Community - The project addresses for example - Public-Private Partnerships, State-Local Partnerships, access, and functional needs?

Project Management - The proposal explains how the project will be managed; how contracts will be managed; how accountability to timelines and grant rules will be monitored and deficiencies corrected. A timeline is provided from grant award to completion. The proposal indicates if SHSP projects funded in the past three years were completed, and provides an explanation if the project was not completed.

Performance Measurement Plan - The proposal identifies how the project's results will be evaluated and who will evaluate them? The proposal describes the overall results that the project is expected to accomplish in qualitative and/or quantitative terms. Some descriptions could include performance measures, national standards, and core capabilities.

Project Replication - Can the project be easily replicated beyond the initial scope or area of initial concern (e.g. training, planning or some other document asset that can be implemented elsewhere)? 


\section{HMA Workshop}

TABLE 3

2018 HMA GRANT GUIDANCE

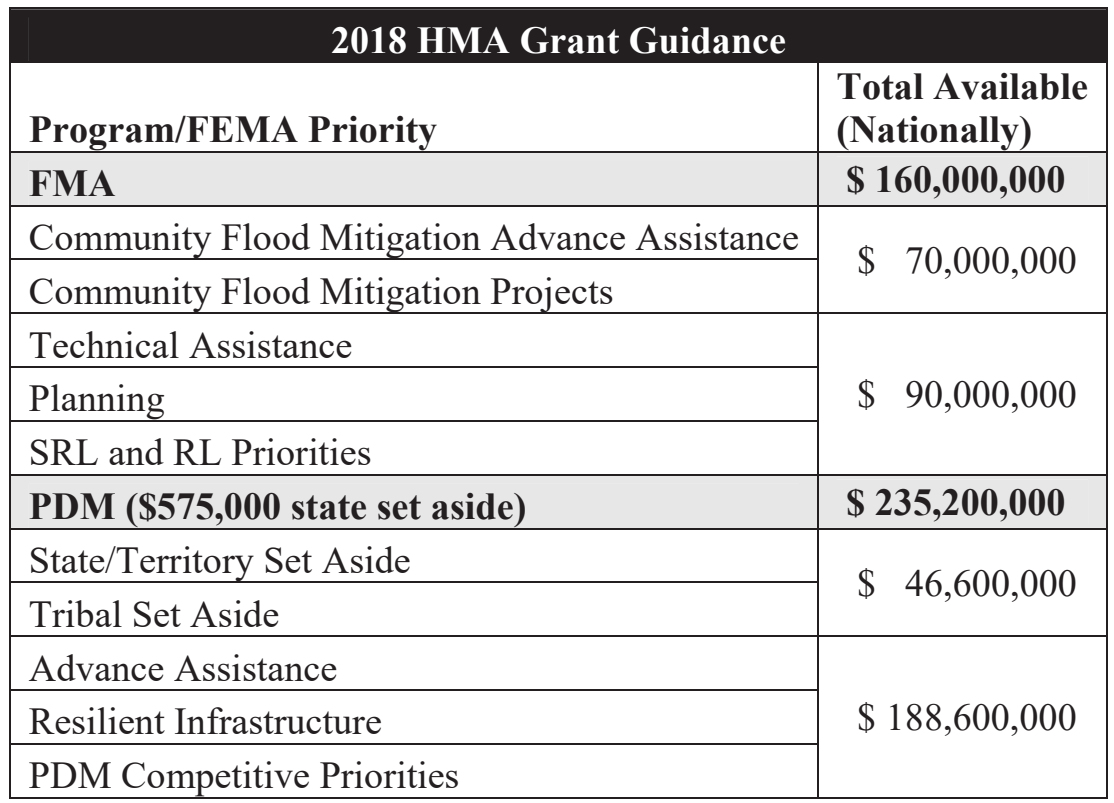

HMA workshop open discussions have resulted in the decision that peer reviewers will not review projects in their region or any in which they may have a conflict of interest. All other outcomes of open discussion are reflected in the evaluation criteria definition, values, and weights.

TABLE 4

\section{HMA CRITERIA DEFINITIONS}

\begin{tabular}{|c|c|}
\hline Mitigation Criteria & Definition \\
\hline Community Impact & $\begin{array}{l}\text { The project reduces impact and benefits the community through protection } \\
\text { of critical infrastructure, facilities, and public/private structures within } \\
\text { single or multiple jurisdictions. }\end{array}$ \\
\hline $\begin{array}{l}\text { Risk Reduction of High } \\
\text { Risk Hazard(s) }\end{array}$ & $\begin{array}{l}\text { The project reduces risk from hazard(s) identified in regional all hazards } \\
\text { mitigation plan. }\end{array}$ \\
\hline $\begin{array}{l}\text { Return on Investment } \\
\text { (BCA) }\end{array}$ & $\begin{array}{l}\text { The project meets FEMA eligibility requirement of one or greater benefit } \\
\text { cost ratio. Substantially damaged primary or secondary property } \\
\text { acquisitions are scored higher than the FEMA BCA default of one. }\end{array}$ \\
\hline Project Useful Life & FEMA BCA project useful life for structural projects. \\
\hline Scope of Work & $\begin{array}{l}\text { The scope of work clearly illustrates the project timeline, including } \\
\text { milestones and deliverables as it relates to the performance period. }\end{array}$ \\
\hline Fiscal Stress Index & $\begin{array}{l}\text { Department of Housing and Community Development Fiscal Stress Score. } \\
\text { http://www.dhcd.virginia.gov/images/GoVA/Fiscal\%20Stress\%202016.pdf. }\end{array}$ \\
\hline Mitigation Alternatives & $\begin{array}{l}\text { The applicant demonstrates understanding of project objectives by clearly } \\
\text { articulating at least two feasible mitigation alternatives, and outlines the } \\
\text { project development process. }\end{array}$ \\
\hline
\end{tabular}




\section{Proposal Submission}

The proposal submission process is an administrative/technical task in which different technology is used for SHSP and HMA. Both require managing applications and supporting documentation. SHSP is managed through a combination of proposal submission via Qualtrics $\mathbb{C}$, and support documentation upload via FileMaker ${ }^{\circledR}$, and is a one-time submission. HMA is managed through a MitigationVA.org website which allows applicants to iterate on their proposals and support documents. For both programs, proposal forms are designed to allow applications to capture necessary information for project evaluation.

\section{Eligibility Screening}

Prior to peer review projects are screened by VDEM grants management personnel to ensure all proposals meet eligibility requirements. This period also allows for any Requests for Information (RFI) to be sent to program managers.

SHSP requirements include, but are not limited to:

- National Incident Management System (NIMS) implementation

- Emergency Management Assistance Compact (EMAC) membership

- Alignment with Statewide Communication Interoperable Plan (SCIP), and coordination with the Statewide Interoperability Coordinator (SWIC) and/or Statewide Interoperability Governance Body (SIGB) (communications investments)

- $25 \%$ allocation to Law Enforcement Terrorism Prevention Activities (LETPA)

- At least one investment in support of a Fusion Center, and one in support of cybersecurity

- All projects must meet eligible activity and equipment purchase requirements

HMA requirements include, but are not limited to:

- HMA Applicants must have a FEMA approved mitigation plan, unless the project proposed is for mitigation plan development or update

- All HMA structural projects must have a FEMA defined Benefit/Cost Ratio of 1.0 or greater

- All projects must meet eligible activity requirements

\section{Peer Review}

Peer review occurs over a two week period for SHSP and HMA. For both programs, scores are entered via Qualtrics $\mathbb{C}$, and scores and comments are kept anonymous. Reviewers for SHSP are drawn from a broad emergency management stakeholder pool across the Commonwealth. In 2012 \& 2013 only six senior executives participated in the evaluation process, but starting in 2014 an average of 70 people participated. SME review of projects is coordinated by each region or SME group by the respective regional coordinator or program manager and conducted in a group setting. These groups range on average from 4-12 people and have the discretion to decide to score projects as a group or individually. Hazard Mitigation Assistance peer review does not include a separate SME review, and the pool of reviewers is drawn from workshop participants including, from each region, representation from two emergency management, 2 non-emergency management, one planning district commission, and one VDEM planner.

\section{Model Calculations}

The model is based on a multiple-objective decision analysis (MODA) framework, an approach recognized for situations where values, preferences and human judgment are present. MODA is used in decision analysis and risk analysis when problems have multiple objectives, often in conflict, that require quantifying explicit value tradeoffs. MODA integrates objective facts explicitly with value preference judgments. MODA models are well proven to help support policy decisions (Keefer et al., 2007). A MODA model is useful when the decision requires organizing and aggregating many variables in a clear, transparent and accountable way (Ezell, 2007).

In a MODA approach, the objectives are organized into a hierarchy of factors (for this application, project proposal scoring criteria) where the lowest-level objectives are quantified by measurable scoring 
criteria (Kirkwood, 1997). This model is based on stakeholder inputs and the model calculation illustrated in Error! Reference source not found.. To assess the value of a proposal, the following additive value model is used to combine all the criteria where the attribute measure, $\mathbf{x}_{m}$ is the level of the $m_{\text {th }}$ attribute measure, $\mathrm{v}_{\mathrm{m}}\left(\mathrm{x}_{m}\right)$ is the value of the attribute value function (Error! Reference source not found.) at level $\mathrm{x}_{m}$, and $\mathrm{w}_{m}$ is the weight (Error! Reference source not found., Error! Reference source not found.) associated with that attribute measure.

$v(x)=\sum_{m=1}^{n} w_{m} v_{m}\left(x_{m}\right)$

FIGURE 1

CRITERIA VALUE FUNCTIONS EXAMPLE

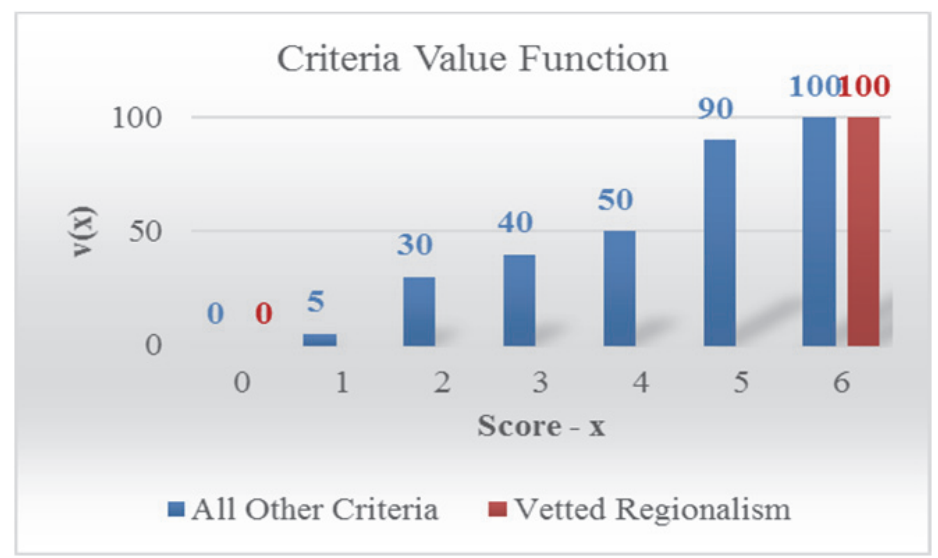

\section{FIGURE 2 \\ SHSP CRITERIA WIEGHTS}

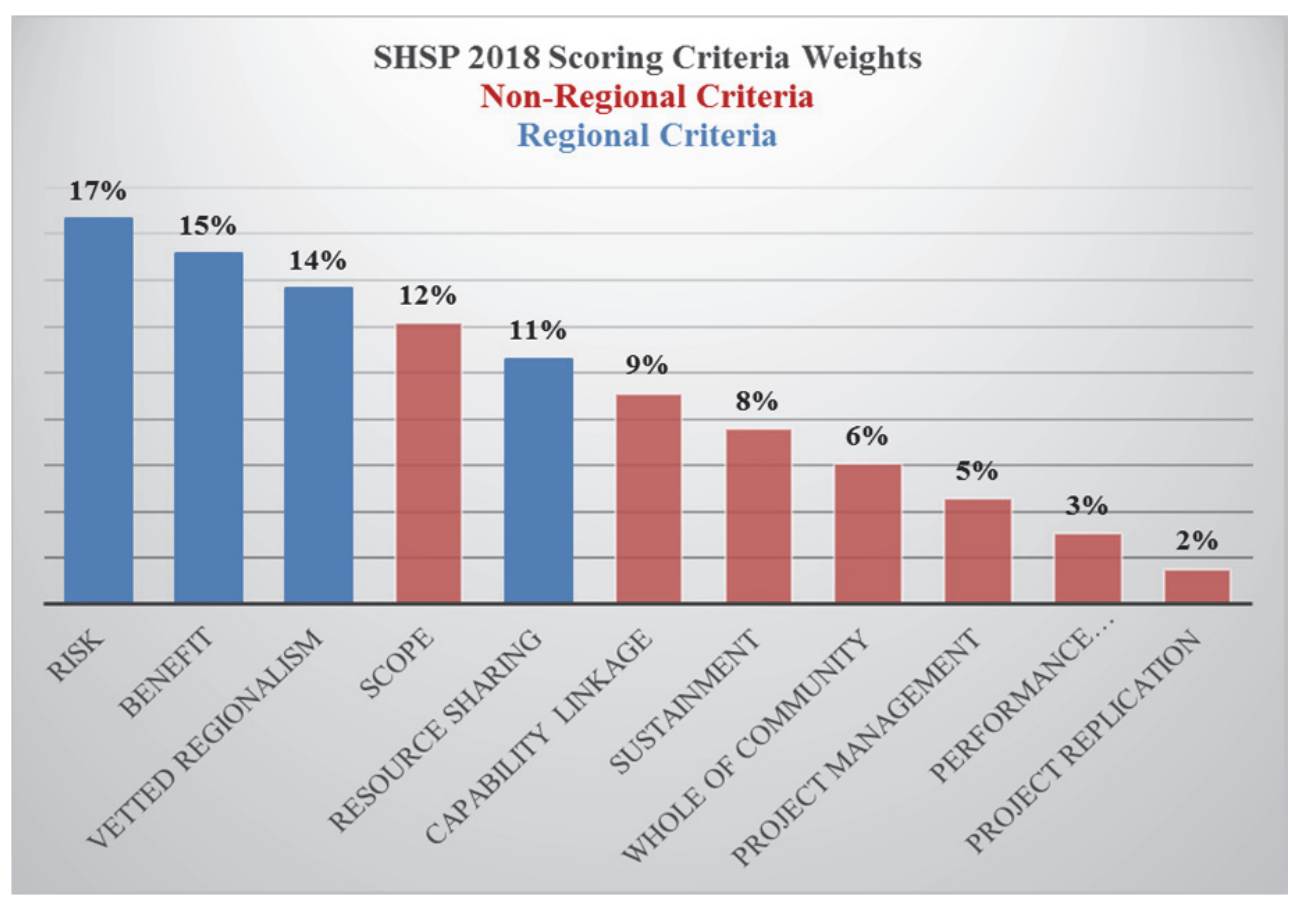


FIGURE 3

HMA CRITERIA WEIGHTS

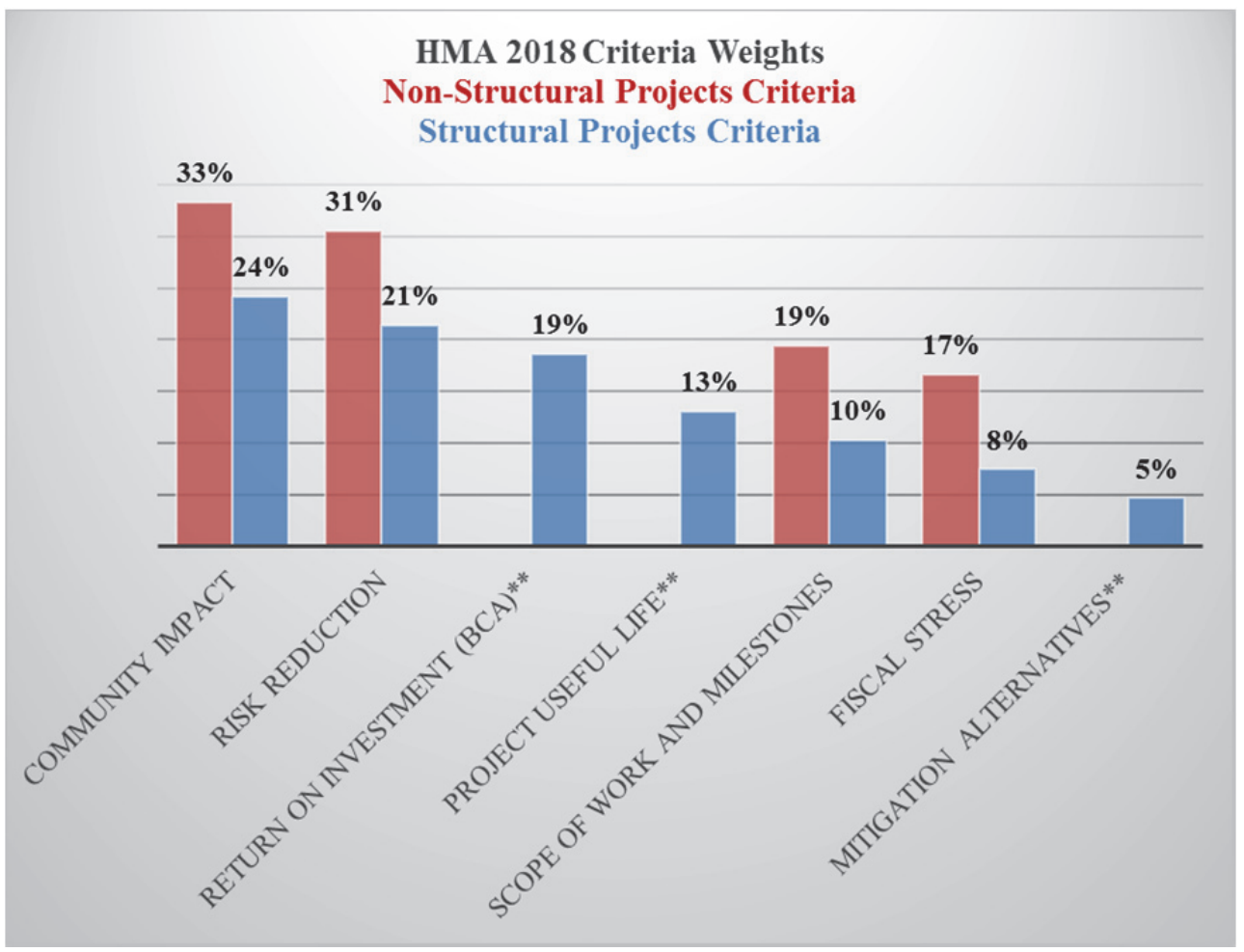

\section{Analysis}

Peer reviewer scores and comments are imported into FileMaker ${ }^{\circledR}$, a web enabled database system, to allow for organization of projects based on attributes of interest: total score, benefit-cost ratio, priority, region, investment area, mission area, and core capability. Additionally, a total score is calculated based on the model. The total score is divided by the project cost for a benefit-cost ratio.

Each grant has certain parameters that influence decision making beyond the project score and benefit-cost ratio which are analyzed.

For SHSP these are as follows:

- $25 \%$ law enforcement requirement

- $10 \%$ available funding cap on CERT projects

- Elimination of projects scored in the bottom $40 \%$

For PDM these are as follows:

- $\$ 4$ million for mitigation projects

- Up to $\$ 200,000$ per Applicant for Advance Assistance

- $\$ 10$ million for Resilient Infrastructure projects

- $\$ 400,000$ for new mitigation plans consistent with 44 CFR Part 201

- $\$ 300,000$ for State/territorial and multi-jurisdictional local or tribal mitigation plan updates consistent with 44 CFR Part 201

- $\$ 150,000$ for single jurisdiction local or tribal mitigation plan updates consistent with 44 CFR Part 201

For FMA these are as follows:

- Up to $\$ 100,000$ per Applicant for community mitigation Advance Assistance applications;

- Up to $\$ 10$ million per Applicant for community mitigation project applications;

- $\$ 50,000$ for technical assistance for Recipients to which FEMA obligated at least $\$ 1$ 
- million in FMA awards in FY 2017;

- $\$ 100,000$ Federal cost share per Applicant with a maximum of $\$ 50,000$ Federal cost share for State mitigation plan updates and $\$ 25,000$ Federal cost share for local mitigation plans.

\section{Funding Decision}

Model outcomes and analysis based on predefined conditions are presented to decision makers enabling them to visualize how projects rank amongst their peers. The modeled results are not the final decision. This is the starting point for discussion with the senior leadership committee. In some cases, proposals were funded due to factors beyond the consideration of the model. The model itself serves as a tool for informing the process and investment justifications. In some cases, the analysis of the data captured allows VDEM administrators to easily identify projects in which funding decisions may not have been consistent with their objectives, enabling them to reconsider a project proposal and the justification for a decision.

For SHSP the decision has, with few exceptions, been to rank projects by benefit-cost ratio and fund all projects with available funding. CERT projects that exceed the cap may be funded at reduced amounts when appropriate. For HMA, project benefit-cost is calculated and examined but not used for the final decision. For HMA projects FEMA uses the SAA ranking and Federal priorities and guidelines to make funding decisions. Due to the FEMA priority structure projects are ranked by FEMA priority, and then benefit score.

\section{Projects Submitted to FEMA}

Once a final decision has been made, VDEM submits the best performing projects to FEMA. Once submitted an announcement is sent to all applicants with the final decision. This is an administrative task outside the scope of this paper, but is none-the-less a critical part of the process.

\section{CONCLUSIONS}

The model development process enables senior leadership to make decisions consistent with federal requirements, and the needs and values of the state and local emergency management community. A better organized project portfolio, customized data summaries, and project scoring analysis provide the tools necessary for a successful grant administration process. Refining the process with every grant cycle encourages community engagement and highlights areas of improvement that may have otherwise gone overlooked. Engaging the community and improving the efficiency in which critical yet limited resources are utilized improves preparedness across all mission areas and core capabilities, and reduces reliance on Federal funds.

\section{ENDNOTE}

1. HMGP grants are not included in the discussion beyond the introduction section of this paper as the 2018 Hurricane Florence and Tropical Storm Michael \& Florence are still in process. 


\section{REFERENCES}

Department of Homeland Security. (2015). National Preparedness Goal (Second Edition). Retrieved December 3, 2018, from https://www.fema.gov/media-library-data/14437996151712aae90be55041740f97e8532fc680d40/National_Preparedness_Goal_2nd_Edition.pdf

Department of Homeland Security. (2018a). Notice of Funding Opportunity FY 2018 Flood Mitigation Assistance. Retrieved from https://www.fema.gov/media-library-data/1543426158982442d3743052e6ab476094f8019ff9ea4/FY2018FMANOFO_LH.PDF

Department of Homeland Security. (2018b). Notice of Funding Opportunity (NOFO) Fiscal Year (FY) 2018 Homeland Security Grant Program (HSGP). Retrieved from https://www.fema.gov/medialibrarydata/15265788097677f08f471f36d22b2c0d8afb848048c96/FY_2018_HSGP_NOFO_FINAL_50 8.pdf

Department of Homeland Security. (2018c). Notice of Funding Opportunity FY 2018 Pre-Disaster Mitigation. Retrieved from https://www.fema.gov/media-library-data/1543426158991442d3743052e6ab476094f8019ff9ea4/FY2018PDMNOFO_lh.pdf

Ezell, B.C. (2007). Infrastructure Vulnerability Assessment Model (I-VAM). Risk Analysis, 27(3), 571583. DOI: $10.1111 /$ j.1539-6924.2007.00907.x

Federal Emergency Management Agency. (2015). Hazard Mitigation Assistance Guidance. Retrieved from https://www.fema.gov/media-library-data/142498316544938f5dfc69c0bd4ea8a161e8bb7b79553/HMA_Guidance_022715_508.pdf

Keefer, D., Kirkwood C. W., \& Corner J. L. (2007). Perspective on Decision Analysis Applications. In W. Edwards, R. Miles, \& D. von Winterfeldt, (Eds.) Advances in Decision Analysis. Cambridge, UK: Cambridge University Press.

Kirkwood, C. W., (1997). Strategic Decision Making: Multiobjective Decision Analysis with Spreadsheets. Belmont, California: Duxbury Press.

Virginia Department of Emergency Management. (2018a). FY 2018 Homeland Security Grant Program Regional Grant Workshops. Retrieved from http://www.vaemergency.gov/homeland-securitypublic-safety-stakeholders-grant-workshops/

Virginia Department of Emergency Management. (2018b). Hazard Mitigation Assistance Grants: 2018 Regional Grant Stakeholder Workshops. Retrieved from http://www.vaemergency.gov/wpcontent/uploads/2018/05/Hazard-Mitigation-Assistance-Regional-Workshop-PowerPoint.pdf

Virginia Department of Emergency Management. (2017). The Virginia Department of Emergency Management Distributed \$84 Million in Federal Grants in Fiscal Year 2017. Retrieved from http://www.vaemergency.gov/virginia-department-emergency-management-distributed-84million-federal-grants-fiscal-year-2017/ 